\title{
A comparative examination of odontogenic gene expression in both toothed and toothless amniotes
}

\author{
Alexis J. Lainoff ${ }^{(1)},{ }^{*}$, Jacqueline E. Moustakas-Verho ${ }^{(2)}$, Diane $\mathrm{Hu}^{(1)}$, Aki Kallonen ${ }^{(3)}$, Ralph \\ S. Marcucio(1), and Leslea J. Hlusko(4) \\ (1)Department of Orthopaedic Surgery, University of California, San Francisco, San Francisco, \\ USA 94110. \\ (2)Institute of Biotechnology, University of Helsinki, Helsinki, FI 00014. \\ (3)Department of Physics, University of Helsinki, Helsinki, FI 00014. \\ (4)Department of Integrative Biology, University of California, Berkeley, Berkeley, USA 94720
}

\section{Abstract}

A well-known tenet of murine tooth development is that BMP4 and FGF8 antagonistically initiate odontogenesis, but whether this tenet is conserved across amniotes is largely unexplored.

Moreover, changes in BMP4-signaling have previously been implicated in evolutionary tooth loss in Aves. Here we demonstrate that Bmp4, Msxl, and Msx2 expression is limited proximally in the red-eared slider turtle (Trachemys scripta) mandible at stages equivalent to those at which odontogenesis is initiated in mice, a similar finding to previously reported results in chicks. To address whether the limited domains in the turtle and the chicken indicate an evolutionary molecular parallelism, or whether the domains simply constitute an ancestral phenotype, we assessed gene expression in a toothed reptile (the American alligator, Alligator mississippiensis) and a toothed non-placental mammal (the gray short-tailed opossum, Monodelphis domestica). We demonstrate that the Bmp4 domain is limited proximally in $M$. domestica and that the $F g f 8$ domain is limited distally in A. mississippiensis just preceding odontogenesis. Additionally, we show that $M s x 1$ and Msx2 expression patterns in these species differ from those found in mice. Our data suggest that a limited Bmp4 domain does not necessarily correlate with edentulism, and reveal that the initiation of odontogenesis in non-murine amniotes is more complex than previously imagined. Our data also suggest a partially conserved odontogenic program in $T$. scripta, as indicated by conserved Pitx2, Pax9, and Barxl expression patterns and by the presence of a Shh-expressing palatal epithelium, which we hypothesize may represent potential dental rudiments based on the Testudinata fossil record.

\section{Introduction}

Two key problems at the intersection of evolutionary and developmental biology are how complex organs such as teeth are formed and how variable morphology is generated. One method for identifying unknown components of complex genetic pathways is to investigate

*Correspondence to, UCSF/SGFH, 1001 Potrero Ave., Bldg 9, Rm 346, San Francisco, CA 94110. lainoffa@ orthosurg.ucsf.edu. Phone: (415) 206 - 5362. Fax: (415) 206-8244. 
examples in nature where development has been disrupted. Despite the strong selective pressure on teeth, several vertebrates have lost their dentitions during evolution, including birds, baleen whales, anteaters, several lineages of fish, and turtles. Discrepancies in genetic pathways or in developmental timing between toothed taxa and toothless taxa can be used as tools for identifying aberrant changes linked to tooth agenesis.

Classic embryological studies of mice have revealed that teeth develop as a result of a set of interactions between the dental epithelium and underlying neural crest-derived mesenchyme (reviewed in Jernvall and Thesleff, 2000; Cobourne and Sharpe, 2003; Tucker and Sharpe, 2004). Murine odontogenesis is initiated when signaling molecules expressed in the dental epithelium signal to the underlying mesenchyme, rendering it dental mesenchyme (Mina and Kollar, '87; Lumsden, '88). The first visual marker of tooth development in the mouse is the dental lamina stage, at which point an invagination of the dental epithelium can be observed. The bud, cap, bell, and eruption stages of tooth development follow. The stage that is most relevant to our work is the period before and during the first morphological indication of tooth development; for the mouse, that is the formation of the dental lamina, while for some more basal amniotes, there is no dental lamina formation and/or the morphogenesis of teeth proceeds in an entirely different manner, such as with evaginating (rather than invaginating) tooth buds.

Studies conducted in mouse models suggest that the position where teeth will develop is established by the interactions of two mutually antagonistic signaling molecules, FGF8 and BMP4 (Neubüser et al., '97). Early in development, the oral epithelium of the mouse mandible is broadly divided into two domains: $F g f 8$ and $F g f 9$ mark the proximal (lateral) region, defining the presumptive molar field, while Bmp4 marks the distal (mesial) area, delineating the presumptive incisor field (Åberg et al., '97; Kettunen and Thesleff '98). Although how these epithelial expression domains are established is still unknown, they are deployed early in development, prior to the formation of the face (Haworth et al., 2004). Ultimately, the signaling molecules produced by these epithelially-expressed genes establish the major tooth fields by regulating the expression of homeobox genes in the underlying mesenchyme. Fgf8 induces expression of Pax 9 and Barxl in the mesenchyme (Neubüser et al., '97; Tucker et al., '98), as well as epithelial expression Pitx2, a marker for the dental lamina band (St. Amand et al., 2000). Pax9 and Pitx2 are both necessary for tooth development to proceed past the bud stage (Peters et al., '98; Lin et al., '99; Lu et al., '99).

A significant regulator of early tooth development is the Bmp4-Msx pathway. In mice, Bmp4 is expressed in the oral epithelium in the beginning stages of odontogenesis and shifts to the mesenchyme just before the bud stage is broached (Vainio et al., '93); this change is concurrent with a shift of odontogenic potential from the oral epithelium to the oral mesenchyme (Mina and Kollar, '87). Bmp4 induces expression of Msxl and Msx2 in the dental mesenchyme, and Msxl is in turn required for Bmp4 expression in the mesenchyme, forming a positive feedback loop (Vainio et al., '93; Satokata and Maas, '94; Chen et al., '96). In Msxl-/- mice, mesenchymal but not epithelial Bmp4 expression ceases (Chen et al., '96) and tooth development arrests at the bud stage, the same stage that Bmp4 expression normally shifts from the epithelium (Satokata and Maas, '94; Chen et al. '96). Although $M s x 1$ and Msx2 appear to have a somewhat redundant role in early odontogenesis, tooth 
development arrests even more prematurely, at the dental lamina stage, in Msx1-/-; Msx2-/mouse mutants (Bei and Maas, '98).

Several studies have implicated a deficit of BMP4 signaling as the evolutionary source of tooth loss in the Aves lineage (Chen et al., 2000; Harris et al., 2006). Although expression of several odontogenic genes was found to be conserved in the chick oral cavity, mesenchymal expression of $M s x 1 / 2$ and epithelial expression of Bmp4, was missing from the proximal region of the chick mandible in contrast to expression domains found in mice (Chen et al., 2000). However, both the Msx expression and the development of tooth-like appendages in chick mandibular mesenchyme were partially rescued following the application of exogenous BMP4 (Chen et al., 2000). These experiments lent evidence to the hypothesis that although quiescent, early signaling pathways remain inducible in Aves, and implicated a deficit of BMP4 signaling in the proximal mandibular mesenchyme as the key variable in avian tooth loss. This hypothesis was further supported by the observation that in talpid ${ }^{2}$ chick mutants (affected gene unknown), which form structures similar in shape to archosaurian (crocodilian) first-generation teeth, the expression domains of both $F g f 8$ and Bmp4 are expanded and coincide, in comparison to wild-type chick embryos (Harris et al., 2006), a significant finding because $F g f 8$ and $B m p 4$ are thought to antagonistically initiate odontogenesis in mice (Neubüser et al., '97).

In this study, we first investigate potential mechanisms underlying the loss of teeth in turtles during evolution by examining the red-eared slider turtle, Trachemys scripta elegans, for histological and molecular evidence of tooth development. All modern turtles are edentulous, but small, peg-like teeth are present in fossil specimens dating from 174 to 220 million years ago. Turtles provide a window into understanding early tooth development that chicks do not, as several of the oldest known turtles had a multi-rowed dentition (Gaffney and Meeker, '83; Gaffney et al., '87; Gaffney and Jenkins, '90; Rougier et al., '95; Li et al., 2008), a phenotype that has not been reported to date in the avian fossil record. Additionally, we take a preliminary step towards addressing whether the antagonistic initiation of tooth development by BMP4 and FGF8 is conserved across amniotes, as well as whether limited Bmp4 expression is a good indicator of subsequent tooth loss, by determining whether Bmp4, Msxl, Msx2, and Fgf8 expression is conserved in an edentate reptile (T. scripta), a toothed reptile (the American alligator, Alligator mississippiensis), and a toothed nonplacental mammal (the gray short-tailed opossum, Monodelphis domestica) during developmental stages equivalent to embryonic stage 10.5 (E10.5) in mice.

\section{Methods and Materials}

\section{Embryo collection}

Both T. scripta and A. mississippiensis eggs were obtained with a permit from the Harvey Kliebert Turtle and Alligator Farm and the Rockefeller Wildlife Refuge, respectively. T. scripta eggs were incubated at $25-30^{\circ} \mathrm{C}$ and A. mississippiensis eggs incubated at $30-35^{\circ} \mathrm{C}$ in a 1:1 mixture of water and vermiculite. M. domestica embryos were obtained from a breeding colony managed by Kathleen K. Smith at Duke University (Keyte and Smith, 2009). All embryos were preserved in $4 \%$ paraformaldehyde (PFA), gradually transferred to ethanol or methanol, and stored at $-20^{\circ} \mathrm{C}$. Embryos were euthanized by piercing the 
developing heart tissue. Pregnant mouse dams were euthanized by carbon dioxide asphyxiation followed by cervical dislocation according to protocols approved by UCSF IACUC. Pregnant $M$. domestica females were euthanized as described (Keyte and Smith, 2009) according to protocols approved by Duke University IACUC.

\section{Developmental staging of embryos}

Model organisms house mouse (Mus musculus) and chicken (Gallus gallus domesticus) were staged according to Theiler ('89) and to Hamburger and Hamilton ('51) respectively. T. scripta embryos were staged according to Yntema ('68), A. mississippiensis embryos were staged according to Ferguson ('85), and M. domestica embryos were staged according to Mate et al. ('94) and the K. K. Smith laboratory (see http://www.biology.duke.edu/ kksmithlab for staging series). The embryonic stage of most interest to us is the one at which initiation of odontogenesis occurs; thus we sought to collect stages of different taxa for comparative analysis along this developmental time point. For toothed taxa, we examined embryos at stages just preceding the first morphological indications of tooth development (embryonic stage 30 (e30) in M. domestica (Moustakas, 2011), Ferguson stage 13 (F13) in A. mississippiensis (Ferguson, '85), and E10.5 in M. musculus (Jernvall and Thesleff, 2000)). We estimated stage equivalency between toothless taxa and toothed taxa by referencing non-dental identifying structures in craniofacial development. Yntema stages 13-17 (Y13-17) were examined in T. scripta based on the developmental appearance of craniofacial structures including the broadening and forward growth of the mandibular arches, the forward growth and fusion of the nasal processes, and the fusion of the nasal and maxillary processes; in this paper, we regarded Y14 T. scripta embryos as being equivalent to E10.5 M. musculus embryos based on the presence of maxillary processes large enough to have pushed the nasal pits medially, the presence but incomplete fusion of the nasal pits, and mandibular processes that are prominent but have a discontinuous distal edge. Hamburger and Hamilton stage 22 (HH22) G. gallus embryos were regarded as being equivalent to E10.5 M. musculus based on the same characters.

\section{Cloning}

Total RNA was isolated from T. scripta and A. mississippiensis embryos using TRIzol reagent (Invitrogen). mRNA was generated from total RNA stocks using the Oligotex kit (Invitrogen). cDNA was prepared from mRNA using the GeneRacer ${ }^{\mathrm{TM}}$ kit (Invitrogen). Degenerate polymerase chain reaction was used to isolate $T$. scripta, A. mississippiensis, and $M$. domestica genes. Isolated gene sequences were deposited in Genbank under the following accession numbers: T. scripta Barxl (KJ137001), Pitx2 (KJ137002), Fgf8 (KJ137006) and Shh (KJ137003); A. mississippiensis Bmp4 (KJ137005) and Msx I (KJ137004). M. domestica Msxl sequence is included in the supplemental information. Previously deposited sequences include T. scripta Msxl (EF527275), Msx2 (EF527276), Bmp4 (EF527274), and Pax9 (EF524560); and M. domestica Fgf8 (GU984788) and Msx2 (XM_001370651). 


\section{In situ hybridization}

In situ hybridization was carried out on whole-mount embryos according to Moustakas (2008) and on paraffin-embedded sections according to Albrecht ('97). Digoxigenin- or ${ }^{35} \mathrm{~S}$ labeled riboprobes were generated from linearized plasmids using T3 or T7 polymerase (Roche). For whole-mounts, mRNA expression was detected using alkaline phosphatasecoupled anti-digoxigenin antibody (Roche) and BM Purple (Roche). Turtle Bmp4 and Msx2 and chick $F g f 8$ probes were used with alligator embryos. Images of the radioactive in situ hybridization assays are the product of superimposing the pseudo-colored hybridization signal in Adobe Photoshop (Adobe, San Jose, CA) with a blue nuclear stain (Hoescht Stain, Sigma).

\section{Histological and gross morphological analyses}

For histological analysis, embryos were dehydrated in graded ethanols, cleared with xylenes, embedded in paraffin, and sectioned $(10 \mu \mathrm{M})$. Sections were stained with Eosin Y (Presnell and Schreibman, '97). For gross morphological analysis, embryos were stained with a solution of $0.01 \%$ ethidium bromide in 1 XPBS and were photographed using a Texas Red fluorescent filter on a Leica MZFLIII dissecting microscope with a Leica LEI-750 camera (Leica Microsystems, Germany) and Adobe Photoshop (Adobe, San Jose, CA).

\section{X-ray microtomography}

T. scripta embryos were fixed with 4\% PFA, dehydrated into $70 \%$ ethanol, and dyed with phosphotungstic acid (\#P4006, Sigma) for 24 hours (Metscher, 2009). The samples were scanned using a custom-built $\mu$ CT system Nanotom 180 NF (phoenix|x-ray Systems + Services GmbH, Wunstorf, Germany) with a CMOS flat-panel detector (Hamamatsu Photonics, Japan) and a high-power transmission-type X-ray nanofocus source with a tungsten anode. The samples were imaged with $80 \mathrm{kV}$ acceleration voltage and $180 \mu \mathrm{A}$ tube current. Projection images were acquired over a full circle of rotation with $0.3^{\circ}$ angular interval, and each projection image was composed of the average of 8 transmission images with $500 \mathrm{~ms}$ exposure time. The measurement geometry resulted in an effective voxel size of $4 \mu \mathrm{m}$. The reconstruction from the projection images was performed with reconstruction software datos $\mid \mathrm{x}$ rec supplied by the system manufacturer. The 3D reconstructions were then visualized and virtual slices rendered with Avizo Fire 6.3.

\section{Results}

\section{Early genetic indicators for tooth development are conserved in the $T$. scripta mandible}

Our results establish that Pitx2, Barxl, and Pax9-all early indicators of murine odontogenesis-are expressed in the oral cavity of $T$. scripta in patterns similar to those found in mice.

In Y14 T. scripta jaws, Pitx2 is expressed broadly throughout the oral epithelium (Fig. 1F) but by Y16 its expression is limited to a continuous band (Fig. 1H), similar to Pitx2 expression patterns and timing found in mice (Mucchielli et al., '97). 
Barxl is expressed in the proximal oral mesenchyme of the developing T. scripta maxilla and mandible (Fig. 1I-L), in a pattern akin to the Barxl expression domains found in the proximal mesenchyme of the tooth-forming region of mice (Tissier-Seta et al., '95).

Additionally, Barxl mRNA transcripts concentrate to the edges of the closing choanae (Fig. $1 \mathrm{~K}-\mathrm{L}$ ), notable as Barxl expression is also found in the developing murine palate (Welsh et al., 2007).

Proximal mesenchymal expression of $\operatorname{Pax} 9$ persists in both the upper and lower jaws of $T$. scripta from Y13 to Y16 (Fig. 1M-P), similar to the early mouse odontogenic program, in which Pax9 is expressed broadly in the proximal mesenchyme from the initiation to the bud stage (E11.5-E13.5) (Neubüser et al., '95, http://bite-it.helsinki.fi/).

\section{Bmp4, Msx1, and Msx2 expression is missing from the proximal region, and Fgf8 expression is missing from the distal region, of the $T$. scripta mandible during the putative initiation period of odontogenesis}

The expression pattern of Bmp4 in T. scripta was of particular interest to this investigation because the Bmp4 pathway has been implicated in avian evolutionary tooth loss. Chen et al. (2000) demonstrated that the expression domains of Bmp4 and two of its downstream targets, Msxl and Msx2, do not extend as far proximally in HH27 chick mandibles as they do in mouse mandibles of an equivalent stage, failing to even come into contact with the $F g f 8$ domain in chicks, which is significant because Bmp 4 and $F g f 8$ are considered to, through mutual antagonism, define the tooth-forming region early on in mice (Neubüser et al., '97). Our results indicate that at Y14, a stage of turtle development equivalent to the stage at which odontogenesis is initiated in mice, expression of Bmp4, Msxl, and Msx2 is indeed limited proximally in T. scripta mandibles (Figs. 2B, F, J; 3A; and 4A, F) relative to mice (Figs. 3E and 4E, J; Hill et al., '89; MacKenzie et al., '91; MacKenzie et al., '92; Åberg et al., '97), similar to the previously reported results in chicks (Fig. 3B and 4B, G; Chen et al., 2000).

The limited Bmp4 and Msx2 domains persist until Y16, when expression of each gene becomes broader and more diffuse (Figs. 2A-D, I-L). The limited Msxl domain persists only until Y15, when expression becomes similarly broader and more diffuse before disappearing at Y16 (Fig. 2E-H).

Also in developing $T$. scripta jaws, $F g f 8$ expression is reduced distally in the oral epithelium at Y13 and Y14 (Fig. 2M-N), in contrast to the more extended Fgf8 domain described in both chicks and mice (Fig. 3G, J; Neubüser et al., '97; Kettunen and Thesleff, '98). By Y15, Fgf8 expression has disappeared from the T. scripta jaws (Fig. 2O).

Because reduced Bmp4, Msxl, and Msx2 expression domains have been previously hypothesized to be linked to edentulism in birds (Chen et al., 2000; Harris et al., 2006), the results in T. scripta suggested to us that compromised BMP4 signaling could also bear responsibility for the evolutionary loss of marginal mandibular dentition in the turtle lineage, potentially representing a molecular parallelism. Alternatively, the limited domains could be simply representative of the ancestral condition in reptiles. Although it is well established that $F g f 8$ and $B m p 4$ are required for early odontogenic events to proceed in the mouse 
(Neubüser et al. '97), it is unknown whether these two signaling molecules are required to initiate odontogenesis in other amniote lineages. We sought to address this question by determining whether overlapping Bmp4 and Fgf8 expression domains classically noted in mice just prior to the initiation of odontogenesis are conserved in non-placental vertebrates, namely in a toothed reptile (A. mississippiensis) and in a non-placental mammal $(M$. domestica).

We chose to examine these genes in $M$. domestica because it is a marsupial and thus represents a node of the vertebrate evolutionary tree between placentals and reptiles. Unlike the typical reptilian dentition, $M$. domestica possesses a heterodont set of teeth, including incisors, canines, pre-molars and molars. Additionally, unlike the highly derived dentition of the mouse, $M$. domestica has neither a diastema nor continuously growing incisors, and possesses one deciduous premolar. $M$. domestica thus has a more generalized mammalian dentition, and may in some ways be a better model of human odontogenesis. We chose to examine odontogenic gene expression in e30 M. domestica embryos because that is the stage just preceding the first morphological indication of tooth development, namely when the dental lamina band is apparent at e31 (Moustakas et al., 2011).

We chose to examine these genes in A. mississippiensis because it is a toothed reptile and possesses a more basal dentition characterized by homodonty and teeth with a peg-like morphology, two characteristics ascribed to the dentition of the oldest Testudines (Gaffney, '83; Gaffney et al., '87; Gaffney, '90; Li et al., 2008). The preliminary dentition in the developing alligator is partially transitory (Ferguson, '85), evaginating directly out of the oral epithelium, some before any dental lamina has formed (Westergaard and Ferguson, '86, '87, '90), in a mode of early dental development suggested to be an ancestral condition in non-mammalian tetrapods (Huysseune and Sire, '98; Sire et al., 2002). We chose to examine odontogenic gene expression in F13 A. mississippiensis embryos because that is the stage directly preceding the first morphological indication of tooth development, namely the appearance of two sets of two preliminary teeth on the upper and lower jaws at F14 (Ferguson, '85).

\section{A limited Bmp4 and Fgf8 domain is present in embryonic opossum and alligator mandibles, respectively, despite that both amniotes possess teeth as adults}

In e30 M. domestica mandibles, Bmp4 expression is limited proximally (Fig. 3D), similar to chicks and turtles at equivalent stages (Fig. 3A and B). Fgf8 expression is broad across the proximal mandible of $M$. domestica (Fig. 3I), similar to the mouse (Fig. 3J), but does not extend far enough to overlap with the Bmp4 domain (Fig. 3D).

In F13 A. mississippiensis, Bmp4 expression is broad across the distal mandible (Fig. 3C), similar to the pattern found in mice (Fig. 3E). Fgf8 expression, however, was markedly limited distally in the developing F13 A. mississippiensis mandible (Fig. 3H), in comparison to the mouse (Fig. 3J). 


\section{Msx domains in embryonic opossum and alligator mandibles differ markedly from those found in mice}

Our results indicate that in F13 A. mississippiensis, despite the broad Bmp4 expression (Fig. 3C), Msxl expression is missing from the proximal mandible (Fig. 4C) in comparison to mice (Fig. 4E), a similar result to the chick (Fig. 4B) and turtle (Fig. 4A). Msx2, however, is expressed broadly across the distal mandible (Fig. 4H), similar to the mouse (Fig. 4J)

Msx expression in $M$. domestica yielded an even more unexpected result, different from all the other amniote embryos examined here. The Msxl expression domain was expanded proximally across the e30 M. domestica mandible (Fig. 4D) in comparison to the mouse mandibular expression (Fig. 4E), and Msx2 expression was missing from the entire oral region of the e30 M. domestica mandible, although it was located in the proximal aboral region of the mandible (Fig. 4I).

\section{Epithelium of Y17 T. scripta palatal thickenings marked by Shh expression}

Shh has classically been used as an indicator of early tooth development, although it marks a variety of epithelial organs. Shh is expressed in the dental lamina of the mouse (Bitgood and McMahon, '95; Kettunen and Thesleff, '98) and has been shown to induce epithelial invagination and early dental patterning (Hardcastle et al., '98). In addition, Shh has been found to be expressed in the odontogenic bands of shrews (Yamanaka et al., 2007), voles (Keränen et al., '99), catsharks (Smith et al., 2009), rainbow trout (Fraser et al., 2004) and opossums (Moustakas et al., 2011), and is required for dental lamina band formation in snakes (Buchtovà, 2008) and for the initiation of tooth development in Malawi cichlids (Fraser et al., 2008). In the developing Y17 T. scripta palate, Shh expression marks a halfcircular ring of palatal epithelium, as well as the epithelial edges of the closing choanae (Fig. 5B), the morphology of which is better visualized in sections from a $\mu \mathrm{CT}$ scan of a Y17 T. scripta head (Fig. 5C, E, G, I and Supplemental video 4).

\section{Discussion}

During both evolution and development, the question of how complex structures emerge and the question of how they are lost are indelibly intertwined. In the developing mouse embryo, Bmp4 and $F g f 8$ antagonistically co-initiate tooth development (Neubüser et al., '97), but their early involvement in odontogenesis of other amniotes is largely unexplored. Absence of Bmp4 expression, however, has been linked to evolutionary and developmental edentulism. In chicks, which are toothless, Bmp4 expression is limited proximally compared to mice, but exogenous BMP4 can partially induce tooth development (Chen et al. 2000). In talpid $^{2}$ mutants, which are chick embryos that develop tooth-like rudiments, the expression domains of both $F g f 8$ and Bmp 4 are expanded and coincide in the mandible (Harris et al., 2006), in contrast to wild-type chick mandibles, in which the Bmp 4 expression domain does not extend as far as the $F g f 8$ expression domain (Chen et al., 2000).

In this study we first demonstrate that several indicators of tooth development in mice (reviewed in Tucker \& Sharpe 2004) are found in the oral cavity of T. scripta, including Pitx2, Barx1, Pax9, Fgf8, Bmp4, Msxl, Msx2, and Shh (Fig. 1-2, 5). However, expression of 
Bmp4, Msxl, and Msx2 is missing from the proximal mandibular oral mesenchyme of Y14 T. scripta embryos in comparison to the domains found in mice, a result matching previously reported expression domains described in edentulous HH27 chicks (Chen et al., 2000). In addition, $F g f 8$ expression is missing from the distal oral epithelium of the $T$. scripta mandible as compared to its domain in the mouse mandible, and $F g f 8$ and Bmp4 domains fail to meet in Y13 and Y14 T. scripta embryos. In light of our finding that Bmp4, Msxl and Msx2 expression is also missing from the proximal Y14 T. scripta mandible, we questioned whether the similarly limited domains in both chicks and turtles could represent a molecular parallelism accounting for the evolutionary loss of teeth in both lineages, or whether the shared domains simply represent an ancestral condition. To address this further question, we examined gene expression patterns in a toothed reptile (A. mississippiensis) and in a non-placental mammal (M. domestica) and found that a limited Bmp4 domain (M. domestica) or a limited Fgf8 domain (A. mississippiensis) is present at stages just prior to the first morphological indication of tooth development, demonstrating that coinciding Bmp4 and $F g f 8$ domains directly preceding the initial stages of tooth growth is not required for odontogenesis to proceed in all toothed organisms.

\section{Bmp4, Fgf8, and the balancing act between dental and mandibular development}

There is substantial overlap between the molecular pathways used to build a tooth and those used to build the jaw. However, the specificity that signaling molecules and transcription factors have for orchestrating odontogenesis versus mandibular morphogenesis is not fully characterized. Correctly timed and placed Bmp 4 and $F g f 8$ expression in the mouse is required for proper development of both the dentition (Neubüser et al., '97) and the jaw (Trumpp et al., '99; Tucker et al., '99). Thus, there is merit in discussing the actions of these genes during jaw development as well.

Previous research has demonstrated that the distal expression of Bmp4 and proximal expression of $F g f 8$ in the jaws is highly conserved among vertebrates; this generalized pattern has been described in mice (Vainio et al., '93; Neubüser et al., '97; Kettunen and Thesleff, '98), chickens (Chen et al. 2000), pigs (Armfield et al., 2012), fish (Stock et al., 2006; Fraser et al. 2004) and even lampreys (Shigetani et al., 2005), extant jawless vertebrates that frequently serve as models for pre-gnathostome ancestry. However, some teeth can develop in the absence of these genes: $b m p 4$ is dispensable for pharyngeal tooth development in zebrafish (Wise and Stock, 2010) and knockdown of $f g f 8$ does not significantly impair zebrafish odontogenesis (Jackman et al., 2004). Although slight aberrations in the expression domains of Bmp4 and $F g f 8$ have been previously posited to be causal factors in evolutionary tooth loss (Chen et al. 2000; Harris et al., 2006; Stock et al. 2006), the proximally restricted expression of Bmp4 (Fig. 3) or the distally restricted expression of $F g f 8$ (Fig. 3) that we describe herein suggest no obvious correlation with the loss of the dentition.

A study involving the examination of the Chinese soft-shelled turtle, Pelodiscus sinensis, has attributed evolutionary tooth loss in the turtle lineage to an arrest of odontoblast development caused by a lack of $M s x 2$ expression in the dental mesenchyme (Tokita et al., 2013). The study suggests that tissue outgrowths present in Y17 P. sinensis jaws are 
vestigial teeth, although the true nature of these outgrowths is unknown. We examined $T$. scripta for evidence of outgrowths, and could not find anything morphologically similar in either $\mu \mathrm{CT}$ scans or in H\&E stained sections (Supplemental videos 1-4; H\&E data not shown), suggesting that the two species are dissimilar. Although this study did not identify differences in proximal-to-distal Bmp4, Msx 1 or $M s x 2$ expression between Y13 P. sinensis and the equivalently staged mouse, we found distinct differences between $T$. scripta and the latter.

We demonstrate that the Bmp4 expression pattern is limited proximally in turtle and chick mandibles, a finding that we originally hypothesized could constitute an evolutionary molecular parallelism accounting for the loss of teeth in both lineages. The mandibular expression domain of Bmp4 in A. mississippiensis, a toothed archosaur, is expanded in comparison to the mandibular domains found in the turtle and the chicken, and thus lends support to the hypothesis that changes in BMP4-signaling could have accounted for evolutionary tooth loss in both lineages. However, we also discovered a limited Bmp4 domain in the mandible of $M$. domestica, a toothed amniote, demonstrating that a limited Bmp4 domain does not correlate with tooth loss.

The differences observed in expression of $F g f 8$ in the amniote mandible that we describe here remains unexplained. Missing $F g f 8$ expression has previously been associated with the evolutionary loss of teeth in cypriniform fish (Stock et al., 2006). We demonstrate here that Fgf8 expression is limited distally in both the turtle and the alligator, but not in the chicken, opossum or mouse. In the context of dental development, our conflicting data does not suggest any clear correlation between toothlessness and the mandibular expression Fgf8.

Largely based on gene expression data, Bmp4 has been hypothesized to account for several evolutionary alterations in dental morphology, including the evolutionary transition from heterodonty back to homodonty in the cetacean lineage (Armfield et al., 2012), the evolutionary emergence of a toothless diastema in rodents (Keränen et al., '99; Kassai et al., 2005; Munne et al., 2009) and the evolution of complete tooth loss in birds (Chen et al., 2000). Caution should be taken in drawing conclusions about whether or not Bmp4 mediates these processes based on Bmp4 mRNA transcript localization alone. BMP4 plays a diverse set of roles during embryonic development, and its action is mediated at multiple hierarchical levels to specify different cell and tissue types, such that Bmp4 mRNA expression does not necessarily directly indicate where BMP4 protein is most active.

\section{Msx1/2 in marsupial dental and jaw development}

The expression domains of MsxI and Msx2 that we observed in the M. domestica jaw were unexpected, prompting us to consider their involvement in the genesis of multiple structures. The proximal, rather than distal, mandibular expression domain of $M s \times 2$ and the lack of $M s x 2$ expression in the oral region in M. domestica was a particularly surprising result, as a distal localization of $M s \times 2 \mathrm{mRNA}$ transcripts in the mandible is demonstrated in the mouse (Fig. 4E; MacKenzie et al., '92), chick (Fig. 4B; Chen et al., 2000), alligator and turtle (Fig. $4 \mathrm{~A}, \mathrm{C})$. Marsupials have a very short gestation period; a marsupial neonate is born at a stage of development comparable to E12 of mouse embryogenesis, but must travel to and attach itself to a teat in order to survive. To compensate for the fact that marsupial neonates must 
be able to suckle at a much earlier timepoint, facial development is accelerated as compared to placental mammals. The divergent proximal Msx2 expression domain in M. domestica may be related to the accelerated development of the marsupial mandible. Overexpression of $M s \times 2$ has been demonstrated to inhibit endogenous and BMP4-induced chondrogenesis in mouse mandibles (Semba et al., 2000), and reduced Msx2 has been shown to increase cartilage formation in chick mandibles (Mina et al., '96). Hypothetically, the evolutionary shift of Msx2 from the distal to the proximal mandible in $M$. domestica could have resulted in increased BMP4-promoted chondrogenesis in the distal mandible, allowing the $M$. domestica neonate the increased jaw size and/or morphology that it requires to suckle at such a relatively early developmental stage.

The expression patterns that we discovered in the M. domestica mandible to be diverging dramatically from those found in the mouse also prompted us to consider their potential involvement in the evolution of the murine diastema. In particular, we speculate that $M$. domestica's more proximally extended Msxl expression domain may be indicative of the gene's function in maintaining the teeth that are missing from the murine diastema. In humans, reduced dosage of Msxl results in selective tooth loss, specifically of either the second premolar or the third molar (Varstardis et al., '96; Van den Boogaard et al., 2000; Jumlongras et al., 2001). We suggest that the relatively limited Msxl expression in the mouse jaw in comparison to the opossum jaw is related to the evolutionary loss of the premolars and the fourth molar in the murine lineage.

\section{Multiple roads to tooth formation}

A majority of studies of tooth development examine the mandibular dentition only, largely because the maxillary dentition undergoes morphogenesis concurrently with several other processes such as the closing of the nasal pits, making it difficult to distinguish between what is affecting tooth development and what is affecting upper jaw morphogenesis. This results in a dearth of knowledge about tooth development in the maxilla and in some cases assumptions that teeth in the maxilla are under the same or similar molecular controls as those directing mandibular tooth development. However, some gene knockout and other studies have shown that genetic regulation of maxillary tooth development diverges from mandibular tooth development. For example, when Bmp4 is knocked out in the embryonic mouse neural crest, molar development is arrested at the bud stage in the mandible but maxillary tooth development proceeds unhindered (Jia et al., 2013).

Unlike other toothless lineages, such as the Neornithine lineage, a palatal dentition appears to have survived much longer than the marginal dentition in the lineage leading to turtles (Fig. 6). This may be relevant for understanding the $S h h$-expressing epithelium that we found in the palatal region of Y17 T. scripta embryos. While these regions could be functionally homologous to the mammalian palatal rugae or rugae precursors, both of which express Shh in mice (Bitgood and McMahon, '95), the fossil record of tooth loss in the turtle lineage leads us to consider the possibility that these $S h h$-expressing epithelial regions are vestigial dental rudiments. Paleontological evidence suggests that the turtle lineage became edentulous in a stepwise fashion, retaining its palatal dentition longer than its marginal dentition (Fig. 6). Palatal teeth then disappeared in either the common ancestor of all extant 
turtles or independently in both the cryptodire and pleurodire lineages (Meredith et al., 2013). Indeed, fossil records indicate that palatal teeth were very common among early tetrapods, and evidence exists that there were multiple independent losses of palatal teeth in the clade (Mahler and Kearney, 2005), suggesting that the presence of a palatal dentition is a relatively plastic characteristic.

Although we speculate that the Shh-expressing regions of Y17 palatal epithelium could be rudimentary dental thickenings, there is a discrepancy between this data and the rest of our gene expression findings. Most of the conserved odontogenic gene expression we describe appears on the periphery of the T. scripta oral cavity, rather than within the palate. Pitx2 and Fgf8 both mark the dental lamina in mice (Heikinheimo et al., '94; Semina et al., '96; Mucchielli et al., '97), and appear to mark a similarly peripherally located band that resembles a dental lamina in T. scripta. In contrast, Shh expression in the T. scripta palate appears in a more lingual location. These inconsistent findings lead us to speculate whether the palatal dentitions found in the turtle fossil record were derived from the same set of dental precursors that the outer rows of teeth are derived from. The genetic component of multi-rowed dentitions has been explored in fish (Smith, 2003; Fraser et al., 2008; Shkil et al., 2010), catsharks (Smith et al, 2009) and snakes (Buchtovà et al., 2008; Vonk et al., 2008), and other recent studies have identified the gene $O s r 2$ as a factor that limits tooth development to a single row in mice via antagonism of Bmp4 (Zhang et al., 2009; Zhou et al., 2011). Research on cichlid fish, which have variable rows of teeth, suggests that the program for marginal tooth development is essentially redeployed for initiating the development of subsequent rows of teeth (Fraser et al., 2008), and the multiple tooth rows found in some snakes are also hypothesized to be developmentally homologous (Mahler and Kearney, 2005; Buchtovà et al., 2008). Considering what is known about the development of multiple tooth rows, the spatial patterning of the Pitx2 and Fgf8 genes is inconsistent with the paleontological data showing that the youngest toothed ancestor of modern turtles had palatal teeth but not a set of marginal teeth. If the tooth rows of turtles developed in a similar mode to other animals with multi-rowed dentitions, we would expect to observe indicators for a primary odontogenic band positioned closer to the back of the oral cavity. One hypothetical explanation is that the induction of the marginal and the palatal dentition in toothed turtles was controlled by different developmental programs, and that perhaps the two dentition types are analogous structures with different evolutionary origins, which might lend support to the hypothesis of a dual evolutionary origin of teeth (Soukup et al., 2008).

One inevitable question that arises is whether it is possible to induce tooth development, or to "turn teeth back on" in modern turtles. Researchers have partially rescued odontogenesis in chicks (Kollar and Fisher, '80; Kollar and Mina, '91; Chen et al., 2000; Mitsiadis et al., 2003; Mitsiadis et al., 2006; Cai et al., 2009), although the potential for enamelization may be small due to the loss of enamel-specific genes from the chick genome (Sire et al., 2008). Tooth loss in turtles occurred in the Jurassic (201.6-145.5Ma), much longer ago than tooth loss occurred in any mammals (Cenozoic) or in birds (Cretaceous). Despite the antiquity of edentulism in the turtle lineage, researchers demonstrated that remnants of enamel matrix protein genes AMBN and ENAM remained present in the painted turtle (Chrysemys picta) 
genome, and that vestiges of AMEL were present both in the $C$. picta and the $P$. sinensis genomes (Meredith et al., 2013).

The genes and developmental pathways that lead to the formation of complex structures tend to decay due to mutation over time, such that the re-acquisition of lost forms is highly improbable after more than ten million years (Marshall et al., 1994). The modern interpretation of Dollo's law (Simpson, '53) states that when a complex trait has been lost evolutionarily, it cannot be regained in the same form, although this hypothesis was recently brought into question by a frog's re-evolution of mandibular teeth that had been lost for over 200 million years (Weins, 2011), and the universality of law-like patterns like Dollo's law, being brought into question more generally (Collin and Miglietta, 2008).

Supp. Video 1. CT scan through a Y13 T. scripta head, advancing from a proximal to distal section.

Supp. Video 2. CT scan through a Y14 T. scripta head, advancing from a proximal to distal section.

Supp. Video 3. CT scan through a Y16 T. scripta head, advancing from a proximal to distal section.

Supp. Video 4. CT scan through a Y17 T. scripta head, advancing from a proximal to distal section.

\section{Supplementary Material}

Refer to Web version on PubMed Central for supplementary material.

\section{Acknowledgements}

We thank Rich Schneider, Kristin Butcher, Frank Yang, and Nathan M. Young. We also thank the Harvey Kliebert Turtle and Alligator Farm (Hammond, LA), Ruth M. Elsey at the Rockefeller Wildlife Refuge (Grand Chenier, LA), and Kathleen K. Smith (Duke University, Durham, NC) for generously providing turtle, alligator and opossum embryonic samples, respectively. This research was supported by NSF grant BSC-0616308 and REU supplement; NIH/NIDCR grants R01DE018234, R01DE019638, and T32-DE007306; and the Academy of Finland project number 1259526.

This research was supported by NSF grant BSC-0616308 and REU supplement; NIH/NIDCR grants R01DE018234, R01DE019638, and T32-DE007306; and the Academy of Finland project number 1259526.

\section{Literature Cited}

Åberg T, Wozney J, Thesleff I. Expression patterns of bone morphogenetic proteins (Bmps) in the developing mouse tooth suggest roles in morphogenesis and cell differentiation. Dev Dyn. 1997; 210:383-396. [PubMed: 9415424]

Albrecht, UEG.; Helms, JA.; Lin, H. Visualization of gene expression patterns by in situ hybridization. In: Daston, GP., editor. Molecular and Cellular Methods in Developmental Toxicology. CRC Press; Boca Raton, FL: 1997. p. 23-48.

Armfield BA, Zheng Z, Bajpai S, Vinyard CJ, Thewissen JGM. Development and evolution of the unique cetacean dentition. Peer J. 2013; 1:e24. [PubMed: 23638359]

Bitgood MJ, McMahon AJ. Hedgehog and Bmp genes are coexpressed at many diverse sites of cellcell interaction in the mouse embryo. Dev Biol. 1995; 172:126-138. [PubMed: 7589793] 
Bei M, Kratochwil K, Maas RL. BMP4 rescues a non-cell-autonomous function of Msx1 in tooth development. Development. 2000; 127:4711-4718. [PubMed: 11023873]

Bei M, Maas R. FGFs and BMP4 induce both Msx1-independent and Msx1-dependent signaling pathways in early tooth development. Development. 1998; 125:4325-4333. [PubMed: 9753686]

Buchtová M, Handrigan GR, Tucker AS, Lozanoff S, Town L, Fu K, Diewert VM, Wicking C, Richman JM. Initiation and patterning of the snake dentition are dependent on Sonic Hedgehog signaling. Dev Biol. 2008; 319:132-145. [PubMed: 18456251]

Cai J, Cho SW, Ishiyama M, Mikami M, Hosoya A, Kozawa Y, Ohshima H, Jung HS. Chick tooth induction revisited. J Exp Zool. 2009; 312B:465-472.

Chen YP, Bei M, Woo I, Satokata I, Maas R. Msx1 controls inductive signaling in mammalian tooth morphogenesis. Development. 1996; 122:3035-3044. [PubMed: 8898217]

Chen YP, Zhang Y, Jiang TX, Barlow AJ, St. Amand TR, Hu Y, Heaney S, Francis-West P, Chuong CM, Maas R. Conservation of early odontogenic signaling pathways in Aves. Proc Natl Acad Sci U S A. 2000; 97:10044-10049. [PubMed: 10954731]

Cobourne MT, Sharpe PT. Tooth and jaw: molecular mechanisms of patterning in the first branchial arch. Arch Oral Biol. 2003; 48:1-14. [PubMed: 12615136]

Collin R, Miglietta MP. Reversing opinions on Dollo's Law. Cell. 2008; 23:602-609.

Ferguson, MWJ. Reproductive biology and embryology of the crocodilians. In: Gans, C., editor. Biology of the Reptilia. Vol. Volume 14, Development A. John Wiley \& Sons; Hoboken, NJ: 1985. p. 331-491.

Fraser GJ, Graham A, Smith MM. Conserved deployment of genes during odontogenesis across osteichthyans. Proc Biol Sci. 2004; 271:2311-2317. [PubMed: 15556883]

Fraser GJ, Bloomquist RF, Streelman JT. A periodic pattern generator for dental diversity. BMC Biology. 2008; 6:32. [PubMed: 18625062]

Gaffney ES, Meeker LJ. Skull morphology of the oldest turtles: a preliminary description of Proganochelys quenstedti. Journal of Vertebrate Paleontology. 1983; 3:25-28.

Gaffney ES, Hutchison JH, Jenkins FA, Meeker LJ. Modern turtle origins: the oldest known cryptodire. Science. 1987; 237:289-291. [PubMed: 17772056]

Gaffney ES. The comparative osteology of the Triassic turtle Proganochelys. Bulletin of the American Museum of Natural History. 1990; 194:1-263.

Gaffney ES, Jenkins FA. The cranial morphology of Kayentachelys, an Early Jurassic cryptodire, and the early history of turtles. Acta Zoologica. 2009; 91:335-368.

Hamburger V, Hamilton HL. A series of normal stages in the development of the chick embryo. J Morphol. 1951; 88:49-92. [PubMed: 24539719]

Hardcastle Z, Mo R, Hui CC, Sharpe PT. The Shh signalling pathway in tooth development: defects in Gli2 and Gli3 mutants. Development. 1998; 125:2803-2811. [PubMed: 9655803]

Harris MP, Hasso SM, Ferguson MWJ, Fallon JF. The development of archosaurian first-generation teeth in a chicken mutant. Curr Biol. 2006; 16:371-377. [PubMed: 16488870]

Haworth KE, Healy C, Morgan P, Sharpe PT. Regionalisation of early head ectoderm is regulated by endoderm and prepatterns the orofacial epithelium. Development. 2004; 131:4797-4806. [PubMed: 15342462]

Hedges SB, Poling LL. A molecular phylogeny of reptiles. Science. 1999; 283:998-1001. [PubMed: 9974396]

Heikinheimo M, Lawshé A, Shackleford GM, Wilson DB, MacArthur CA. Fgf-8 expression in the post-gastrulation mouse suggests roles in the development of the face, limbs and central nervous system. Mech Dev. 1994; 48:129-138. [PubMed: 7873403]

Hill RE, Jones PF, Rees AR, Sime CM, Justice MJ, Copeland NG, Jenkins NA, Graham E, Davidson DR. A new family of mouse homeo box containing genes: molecular structure, chromosomal location: and developmental expression of Hox-7.1. Genes Dev. 1989; 3:26-37. [PubMed: 2565278]

Huysseune A, Sire JY. Evolution of patterns and processes in teeth and tooth-related tissues in nonmammalian vertebrates. Eur J Oral Sci. 1998; 106S:437-481. [PubMed: 9541261] 
Jackman WR, Draper BW, Stock DW. Fgf signaling is required for zebrafish tooth development. Dev Biol. 2004; 274:139-157. [PubMed: 15355794]

Jernvall J, Thesleff I. Reiterative signaling and patterning during mammalian tooth morphogenesis. Mech Dev. 2000; 92:19-29. [PubMed: 10704885]

Jia S, Zhou J, Gao Y, Baek JA, Martin JF, Lan Y, Jiang R. Roles of Bmp4 during tooth morphogenesis and sequential tooth formation. Development. 2013; 140:423-432. [PubMed: 23250216]

Jumlongras D, Bei M, Stimson JM, Wang WF, DePalma SR, Seidman CE, Felbor U, Maas R, Seidman JG, Olsen BR. A nonsense mutation in MSX1 causes Witkop syndrome. Am J Hum Genet. 2001; 69:67-74. [PubMed: 11369996]

Kassai Y, Munne P, Hotta Y, Penttilä E, Kavanagh K, Ohbayashi N, Takada S, Thesleff I, Jernvall J, Itoh N. Regulation of mammalian tooth cusp patterning by ectodin. Science. 2005; 309:20672070. [PubMed: 16179481]

Keränen SVE, Kettunen P, Åberg T, Thesleff I, Jernvall J. Gene expression patterns associated with suppression of odontogenesis in mouse and vole diastema regions. Developmental Genes Evolution. 1999; 209:495-506.

Kettunen P, Thesleff I. Expression and function of FGFs-4, -8, and -9 suggest functional redundancy and repetitive use as epithelial signals during tooth morphogenesis. Dev Dyn. 1998; 211:256-268. [PubMed: 9520113]

Keyte, AL.; Smith, KK. Opossum (Monodelphis domestica): a marsupial developmental model. In: Crotty, DA.; Gann, A., editors. Emerging Model Organisms: a Laboratory Manual. Vol. Vol. 1. Cold Spring Harbor Laboratory Press; Cold Spring Harbor, NY: 2009. p. 557-576.

Kollar EJ, Fisher C. Tooth induction in chick epithelium: expression of quiescent genes for enamel synthesis. Science. 1980; 207:993-995. [PubMed: 7352302]

Kollar EJ, Mina M. Role of the early epithelium in the patterning of the teeth and Meckel's cartilage. J Craniofac Genet Dev Biol. 1991; 11:223-228. [PubMed: 1812126]

Li C, Wu XC, Rieppel O, Wang LT, Zhao LJ. An ancestral turtle from the Late Triassic of southwestern China. Nature. 2008; 456:497-501. [PubMed: 19037315]

Lin CR, Kioussi C, O’Connell S, Briata P, Szeto D, Liu F, Izpisúa-Belmonte JC, Rosenfeld MG. Pitx2 regulates lung asymmetry, cardiac positioning and pituitary and tooth morphogenesis. Nature. 1999; 401:279-282. [PubMed: 10499586]

Lumsden AGS. Spatial organization of the epithelium and the role of neural crest cells in the initiation of the mammalian tooth germ. Development. 1988; 103S:155-169. [PubMed: 3250849]

Lu MF, Pressman C, Dyer R, Johnson RL, Martin JF. Function of Rieger syndrome gene in left-right asymmetry and craniofacial development. Nature. 1999; 401:276-278. [PubMed: 10499585]

MacKenzie A, Leeming GL, Jowett AK, Ferguson MWJ, Sharpe PT. The homeobox gene Hox 7.1 has specific regional and temporal expression patterns during early murine craniofacial embryogenesis, especially tooth development in vivo and in vitro. Development. 1991; 111:269285. [PubMed: 1680043]

MacKenzie A, Ferguson MWJ, Sharpe PT. Expression patterns of the homeobox gene, Hox-8, in the mouse embryo suggest a role in specifying tooth initiation and shape. Development. 1992; 115:403-420. [PubMed: 1358591]

Mahler DL, Kearney M. The palatal dentition in squamate reptiles: morphology, development, attachment, and replacement. Fieldiana Zoology. 2006; 108:1-61.

Marshall CR, Raff EC, Raff RA. Dollo's law and the death and resurrection of genes. Proc Natl Acad Sci U S A. 1994; 91:12283-12287. [PubMed: 7991619]

Mate KE, Robinson ES, Vandeberg JL, Pedersen RA. Timetable of in vivo embryonic development in the grey short-tailed opossum (Monodelphis domestica). Mol Reprod Dev. 1994; 39:365-374. [PubMed: 7893485]

Meredith RW, Gatesy J, Springer MS. Molecular decay of enamel matrix protein genes in turtles and other edentulous amniotes. BMC Evolutionary Biology. 2013; 13:20. [PubMed: 23342979]

Metscher BD. MicroCT for comparative morphology: simple staining methods allow high-contrast 3D imaging of diverse non-mineralized animal tissues. BMC Physiology. 2009; 9:11. [PubMed: 19545439] 
Mina M, Gluhak J, Rodgers B. Downregulation of Msx-2 expression results in chondrogenesis in the medial region of the avian mandible. Connect Tissue Res. 1996; 35:79-84. [PubMed: 9084645]

Mitsiadis TA, Chéraud Y, Sharpe P, Fontaine-Pérus J. Development of teeth in chick embryos after mouse neural crest transplantations. Proc Natl Acad Sci U S A. 2003; 100:6541-6545. [PubMed: 12740432]

Mitsiadis TA, Caton J, Cobourne M. Waking-up the sleeping beauty: recovery of the ancestral bird odontogenic program. J Exp Zool. 2006; 306B:227-233.

Moustakas JE, Smith KK, Hlusko LJ. Evolution and development of the mammalian dentition: insights from the marsupial Monodelphis domestica. Dev Dyn. 2011; 240:232-239. [PubMed: 21108317]

Mucchielli ML, Mitsiadis TA, Raffo S, Brunet JF, Proust JP, Goridis C. Mouse Otlx2/RIEG expression in the odontogenic epithelium precedes tooth initiation and requires mesenchymederived signals for its maintenance. Dev Biol. 1997; 189:275-284. [PubMed: 9299120]

Munne PM, Tummers M, Järvinen E, Thesleff I, Jernvall J. Tinkering with the inductive mesenchyme: Sostdc1 uncovers the role of dental mesenchyme in limiting tooth induction. Development. 2009; 136:393-402. [PubMed: 19141669]

Murphy WJ, Eizirik E, O’Brien SJ, Madsen O, Scally M, Douady CJ, Teeling E, Ryder OA, Stanhope MJ, de Jong WW, Springer MS. Resolution of the early placental mammal radiation using Bayesian phylogenetics. Science. 2001; 294:2348-2351. [PubMed: 11743200]

Neubüser A, Koseki H, Balling R. Characterization and developmental expression of Pax9, a pairedbox-containing gene related to Pax1. Dev Biol. 1995; 170:701-716. [PubMed: 7649395]

Neubüser A, Peters H, Balling R, Martin GR. Antagonistic interactions between FGF and BMP signaling pathways: A mechanism for positioning the sites of tooth formation. Cell. 1997; 90:247255. [PubMed: 9244299]

Peters H, Neubüser A, Kratochwil K. Pax9-deficient mice lack pharyngeal pouch derivatives and teeth and exhibit craniofacial and limb abnormalities. Genes Dev. 1998; 12:2735-2747. [PubMed: 9732271]

Presnell, JK.; Schreibman, MP. Humason's Animal Tissue Techniques. The John Hopkins University Press; Baltimore: 1997.

Rougier GW, de la Fuente MS, Arcucci AB. Late Triassic turtles from South America. Science. 1995; 268:855-858. [PubMed: 17792180]

Satokata I, Maas R. Msx 1 deficient mice exhibit cleft palate and abnormalities of craniofacial and tooth development. Nat Genet. 1994; 6:348-356. [PubMed: 7914451]

Semba I, Nonaka K, Takahashi I, Takahashi K, Dashner R, Shum L, Nuckolls GH, Slavkin HC. Positionally-dependent chondrogenesis induced by BMP4 is co-regulated by Sox 9 and Msx 2 . Dev Dyn. 2000; 217:401-414. [PubMed: 10767084]

Semina EV, Reiter R, Leysens NJ, Alward WLM, Small KW, Datson NA, Siegel-Bartelt J, BierkeNelson D, Bitoun P, Zabel BU, Carey JC, Murray JC. Cloning and characterization of a novel bicoid-related homeobox transcription factor gene, RIEG, involved in Rieger syndrome. Nat Genet. 1996; 14:392-399. [PubMed: 8944018]

Shigetani Y, Sugahara F, Kuratani S. A new evolutionary scenario for the vertebrate jaw. BioEssays. 2005; 27:331-338. [PubMed: 15714557]

Shkil FN, Levin BA, Abdissa B, Smirnov SV. Variability in the number of tooth rows in the pharyngeal dentition of Barbus intermedius (Teleostei; Cyprinidae): genetic, hormonal and environmental factors. Journal of Applied Ichthyology. 2010; 26:315-319.

Simpson, GG. The Major Features of Evolution. Columbia University Press; New York: 1953. p. 310-312.

Sire JY, Davit-Beal T, Delgado S, Van der Heyden C, Huysseune A. First-generation teeth in nonmammalian lineages: evidence for a conserved ancestral character? Microsc Res Tech. 2002; 59:408-434. [PubMed: 12430169]

Sire JY, Delgado SC, Girondot M. Hen's teeth with enamel cap: from dream to impossibility. BMC Evolutionary Biology. 2008; 8:246. [PubMed: 18775069]

Smith MM. Vertebrate dentitions at the origin of jaws: when and how pattern evolved. Evolution \& Development. 2003; 5:394-413. [PubMed: 12823456] 
Smith MM, Fraser GJ, Chaplin N, Hobbs C, Graham A. Reiterative pattern of sonic hedgehog expression in the catshark dentition reveals a phylogenetic template for jawed vertebrates. Proceedings of the Royal Society Biological Sciences. 2009; 276:1225-1233. [PubMed: 19141424]

Soukup V, Epperlein HH, Horácek I, Cerny R. Dual epithelial origin of vertebrate oral teeth. Nature. 2008; 455:795-798. [PubMed: 18794902]

St. Amand TR, Zhang Y, Semina EV, Zhao X, Hu YP, Nguyen L, Murray JC, Chen YP. Antagonistic signals between BMP4 and FGF8 define the expression of Pitx1 and Pitx2 in mouse tooth-forming anlage. Dev Biol. 2000; 217:323-332. [PubMed: 10625557]

Stock DW, Jackman WR, Trapani J. Developmental genetic mechanisms of evolutionary tooth loss in cypriniform fishes. Development. 2006; 133:3127-3137. [PubMed: 16831836]

Theiler, K. The House Mouse: Atlas of Embryonic Development. Springer-Verlag; New York: 1989.

Tissier-Seta J-P, Mucchielli M-L, Mark M, Mattei M-G, Goridis C, Brunet J-F. Barx1, a new mouse homeodomain transcription factor expressed in cranio-facial ectomesenchyme and the stomach. Mech Dev. 1995; 51:3-15. [PubMed: 7669690]

Tokita M, Chaeychomsri W, Siruntawineti J. Developmental basis of toothlessness in turtles: Insight into convergent evolution of vertebrate morphology. Evolution. 2013; 67:260-273. [PubMed: 23289576]

Trumpp A, Depew MJ, Rubenstein JLR, Bishop JM, Martin GR. Cre-mediated gene inactivation demonstrates that FGF8 is required for cell survival and patterning of the first branchial arch. Genes Dev. 1999; 13:3136-3148. [PubMed: 10601039]

Tucker AS, Matthews KL, Sharpe PT. Transformation of tooth type induced by inhibition of BMP signaling. Science. 1998; 282:1136-1138. [PubMed: 9804553]

Tucker A, Sharpe P. The cutting-edge of mammalian development; how the embryo makes teeth. Nature Reviews Genetics. 2004; 5:499-508.

Vainio S, Karavanova I, Jowett A, Thesleff I. Identification of BMP-4 as a signal mediating secondary induction between epithelial and mesenchymal tissues during early tooth development. Cell. 1993; 75:45-58. [PubMed: 8104708]

van den Boogaard MJH, Dorland M, Beemer FA, van Amstel HKP. MSX1 mutation is associated with orofacial clefting and tooth agenesis in humans. Nat Genet. 2000; 24:342-343. [PubMed: 10742093]

Vonk FJ, Admiraal JF, Jackson K, Reshef R, de Bakker MAG, Vanderschoot K, van den Berge I, van Atten M, Burgerhout E, Beck A, Mirtschin PJ, Kochva E, Witte F, Fry BG, Woods AE, Richardson MK. Evolutionary origin and development of snake fangs. Nature. 2008; 454:630 633. [PubMed: 18668106]

Wiens JJ. Re-evolution of lost mandibular teeth in frogs after more than 200 million years, and reevaluating Dollo's law. Evolution. 2011; 65:1283-1296. [PubMed: 21521189]

Welsh IC, Hagge-Greenberg A, O’Brien TP. A dosage-dependent role for Spry2 in growth and patterning during palate development. Mech Dev. 2007; 124:746-761. [PubMed: 17693063]

Westergaard B, Ferguson MWJ. Development of the dentition in Alligator mississippiensis: early embryonic development in the lower jaw. Journal of Zoology A. 1986; 210:575-597.

Westergaard B, Ferguson MWJ. Development of the dentition in Alligator mississippiensis: Later development in the lower jaws of embryos, hatchlings and young juveniles. Journal of Zoology. 1987; 212:191-222.

Westergaard B, Ferguson MWJ. Development of the dentition in Alligator mississippiensis: upper jaw dental and craniofacial development in embryos, hatchlings, and young juveniles, with a comparison to lower jaw development. The American Journal of Anatomy. 1990; 187:393-421. [PubMed: 2353674]

Wise SB, Stock DW. bmp2b and bmp4 are dispensable for zebrafish tooth development. Dev Dyn. 2010; 239:2534-2546. [PubMed: 21038444]

Yamanaka A, Yasui K, Sonomura T, Uemura M. Development of heterodont dentition in house shrew (Suncus murinus). Eur J Oral Sci. 2007; 115:433-440. [PubMed: 18028049]

Yntema CL. A series of stages in the embryonic development of Chelydra serpentina. J Morphol. 1968; 125:219-251. [PubMed: 5681661] 
Zhang Z, Lan Y, Chai Y, Jiang R. Antagonistic actions of Msx1 and Osr2 pattern mammalian teeth into a single row. Science. 2009; 323:1232-1234. [PubMed: 19251632]

Zhou J, Gao Y, Zhang Z, Zhang Y, Maltby KM, Liu Z, Lan Y, Jiang R. Osr2 acts downstream of Pax9 and interacts with both Msx1 and Pax9 to pattern the tooth developmental field. Dev Biol. 2011; 353:344-353. [PubMed: 21420399] 


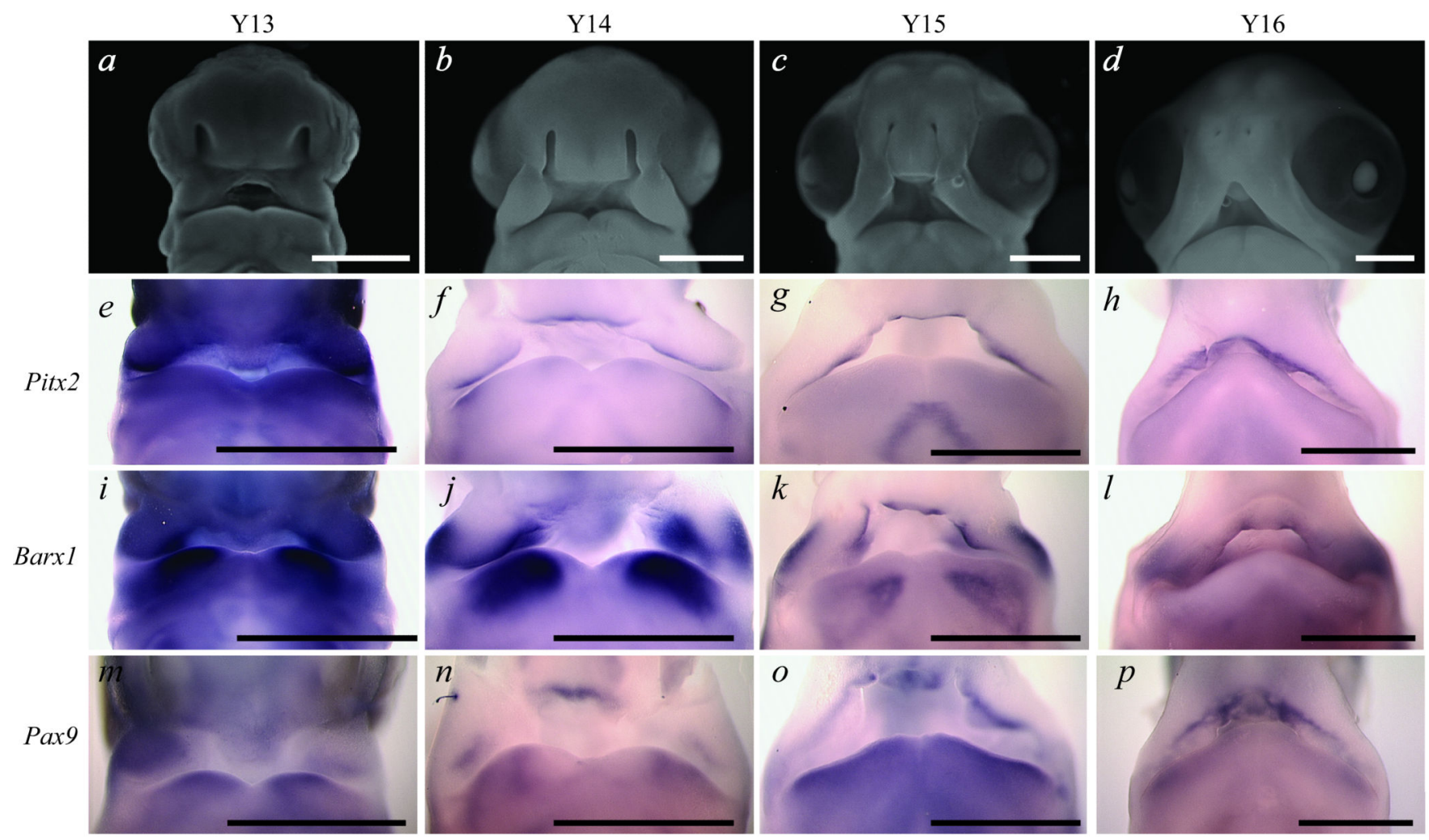

Fig. 1. Conserved expression domains of early tooth development genes in the red-eared slider turtle $T$. scripta

(a-d) For reference, normal facial development in T. scripta from Y13-16. (e-h) Expression of Pitx2. (e-g) From Y13-Y15, Pitx2 is expressed broadly throughout the epithelium, (h) but by Y16 its expression is limited to a continuous band in the jaws. (i-1) Expression of Barxl. (i-j) From Y13-Y14, Barxl is expressed proximally in oral region of both the upper and lower jaws as well as in the proximal, aboral region of the upper jaws. (k) At Y15, Barxl expression is lost from the proximal oral region of the jaws, but persists in the proximal aboral region of the upper jaw as well as on the edges of the closing choanae. (1) By Y16, Barxl expression continues to be prominent in the proximal outer upper jaw as well as on the edges of the closing choanae. (m-p) Expression of Pax9. (m-n) From Y13-Y14, Pax9 is expressed in the proximal region of the upper and lower jaws, as well as in the distal region of the frontonasal prominence. (o-p) From Y15-Y16, Pax9 is expressed broadly throughout the oral cavity. Scale bar $=1 \mathrm{~mm}$. 


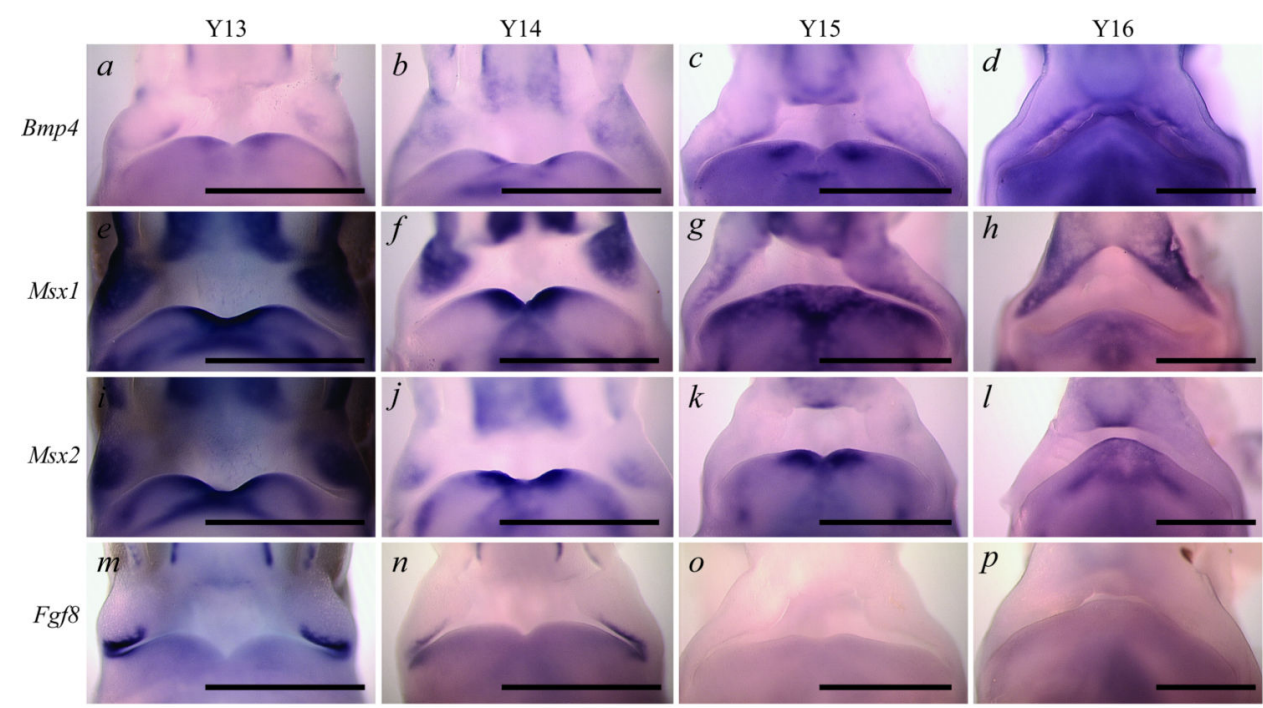

Fig. 2. Bmp4, Msx 1, and Msx2 expression is missing from the proximal region, and $F g f 8$ expression is missing from the distal region, of the $T$. scripta mandible during the putative initiation period of odontogenesis

(a-d) Expression of Bmp4. (a-c) mRNA transcripts of Bmp4 are found in the distal-most region of the developing mandible only. (d) By Y16, there is diffuse Bmp4 expression throughout the mandible. (e-h) Expression of Msxl. (e-f) At Y13 and Y14, Msxl expression is limited to the distal-most region of the developing mandible. (g) By Y15, the Msxl domain has become more diffuse and spread throughout the entire lower jaw; (h) however, by Y16, mandibular Msxl expression has largely disappeared. (i-1) Expression of Msx2. (i-k) From Y13-Y15, Msx2 is expressed only in the distal-most region of the mandible. (1) By Y16, Msx2 is expressed more broadly and diffusely in the distal mandible. (m-p) Expression of Fgf8. (m-n) At Y13 and Y14, Fgf8 expression is found only in the most proximal regions of the developing mandible. (o-p) By Y15 and Y16, Fgf8 expression has disappeared from the lower jaw. Scale bar $=1 \mathrm{~mm}$. 


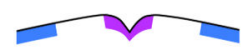

Turtle
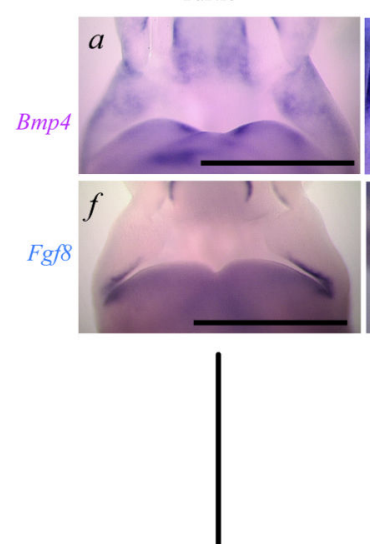

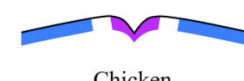

Chicken
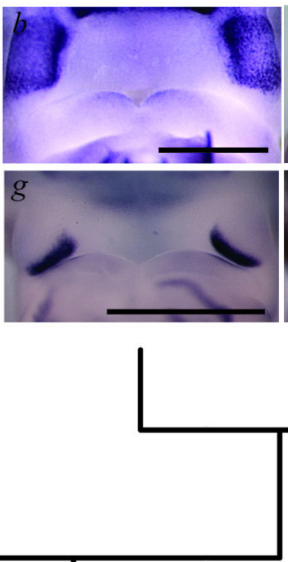

260 mya

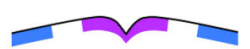

Alligator
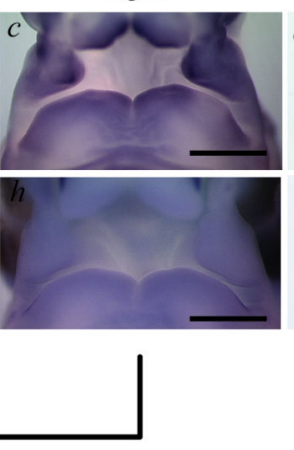

250 mya

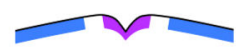

Opossum
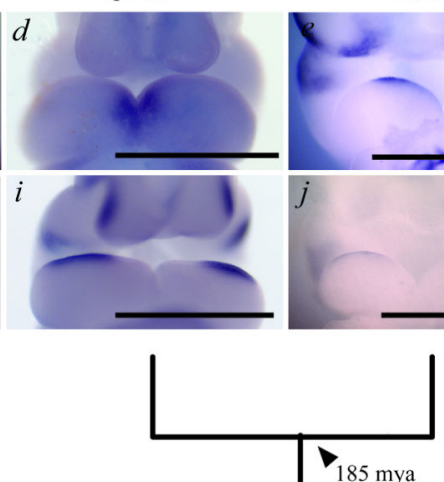

Mouse

185 mya
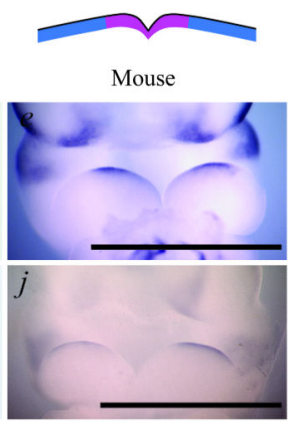

Fig. 3. A limited Bmp4 and Fgf8 domain is present in embryonic opossum and alligator mandibles, respectively, despite that both taxa possess teeth as adults

(a-e) Comparative expression of Bmp4 across stage- matched amniotes. Expression of Bmp4 is limited proximally in Y14 T. scripta (a), HH22 G. gallus (b) and e30 M. domestica (d), in comparison to the broader Bmp4 domain found in both E10.5 M. musculus (e) and F13 A. mississippiensis (c). (f-j) Comparative expression of $F g f 8$ across stage-matched amniotes. Expression of Fgf8 is limited distally in Y14 T. scripta (f) and F13 A. mississipiensis (h). Fgf8 is expressed broadly in the proximal mandible of HH22 G. gallus (g), e30 M. domestica (i) and E10.5 M. musculus (j). Phylogenetic relationships after Murphy et al. (2001) and Hedges and Poling (2002). Scale bar $=1 \mathrm{~mm}$. 

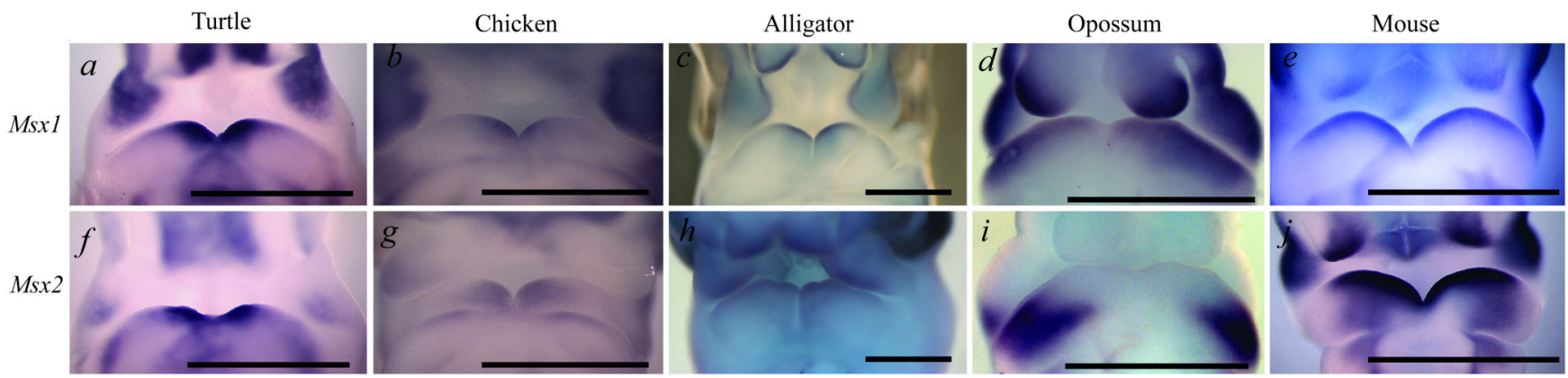

Fig. 4. Msx domains in embryonic opossum and alligator mandibles differ markedly from those found in mice

(a-e) Comparative expression of Msxl across stage-matched amniotes. Expression of $M s x I$ is limited proximally in (a) Y14 T. scripta, (b) HH22 G. gallus and (c) F13 A.

mississipiensis. (d) Msxl is expressed broadly along the proximal-to-distal axis of the e30 M. domestica mandible. (e) Msxl is expressed in the distal mandible of e30 M. musculus. (fj) Comparative expression of $M s \times 2$ across stage-matched amniotes. (f) $M s x 2$ expression is limited proximally in Y14 T. scripta. (g) Msx2 expression is limited proximally in $\mathrm{HH} 22$ G. gallus. (h) Msx2 is expressed broadly in the distal F13 A. mississipiensis mandible. (i) Msx2 is missing from the entire odontogenic region of the e $30 \mathrm{M}$. domestica mandible, although its expression appears prominently in the proximal mandible underlying the odontogenic region. (j) Msx2 is expressed broadly in the distal E10.5 M. musculus mandible. Scale bar = $1 \mathrm{~mm}$. 

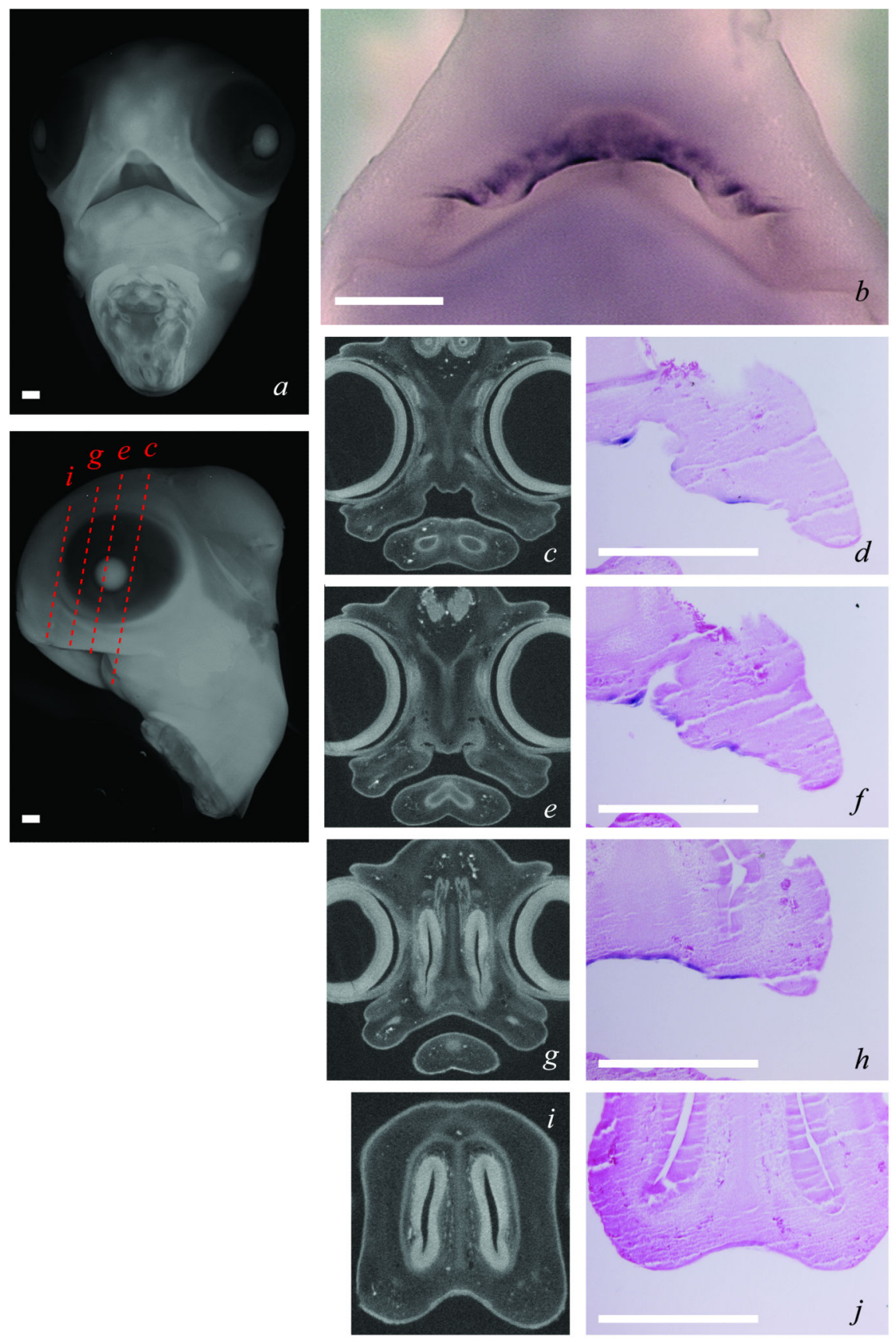

Fig. 5. Epithelium of Y17 T. scripta palate is marked by Shh expression (b, d, f, h, j) Shh expression in a whole mount Y17 T. scripta embryo that was subsequently dehydrated, paraffin-sectioned, and stained with Eosin Y. (c, e, g, i) Morphologically comparable sections clipped from a $\mu \mathrm{CT}$ scan of a Y17 T. scripta embryo accompany the gene expression sections ( $\mu \mathrm{CT}$ video available in the supplementary material). (a) Gross morphology of a Y17 T. scripta embryonic head photographed from an anterior angle. (b) Shh expression marks the developing palate in a whole mount Y17 T. scripta embryo photographed from an anterior angle. (c-d) Shh expression marks the edges of the open 
choanae epithelium as well as two localizations of palatal epithelium. (e-f) Shh expression marks the epithelium where the choanae have closed as well as two patches of palatal epithelium labial to the choanae. (g-h) Shh expression marks the epithelium of the palate in a continuous line. (i-j) Although the accompanying $\mu \mathrm{CT}$ scan image reveals invaginations of palatal epithelium, Shh expression is missing from this region. Scale bar $=500 \mathrm{um}$. 

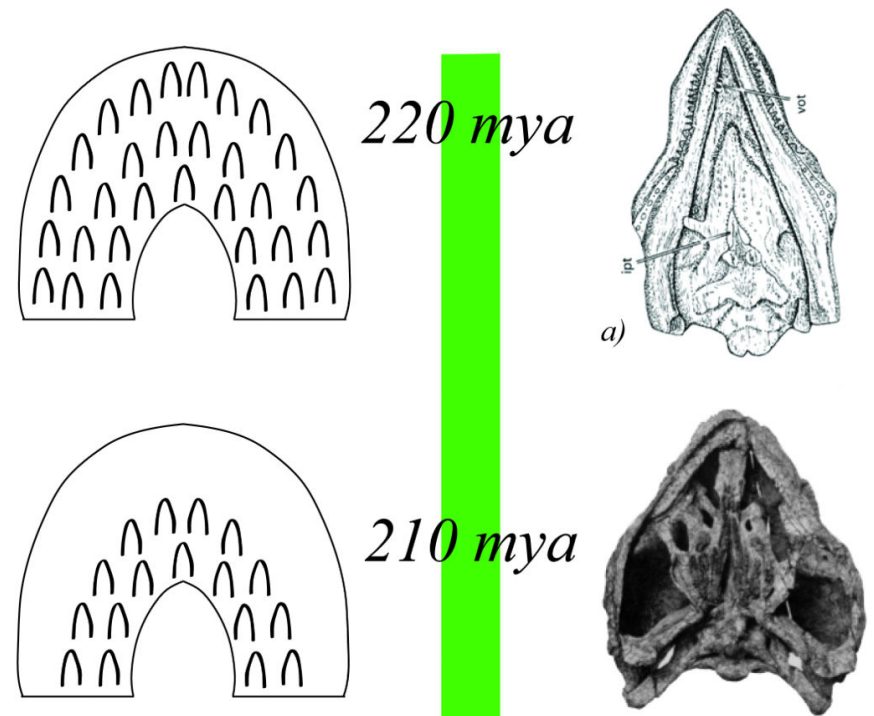

b)
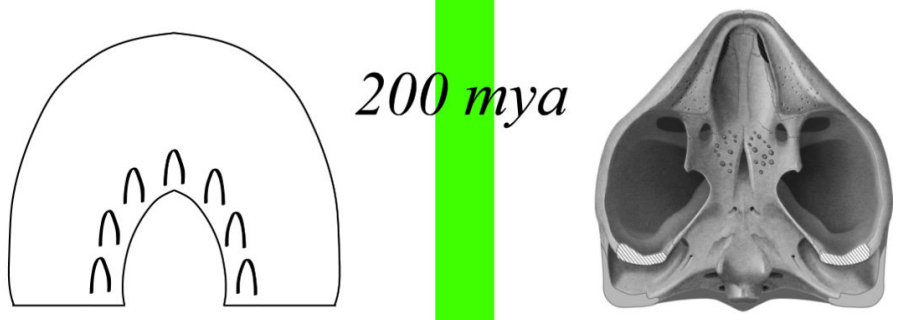

c)

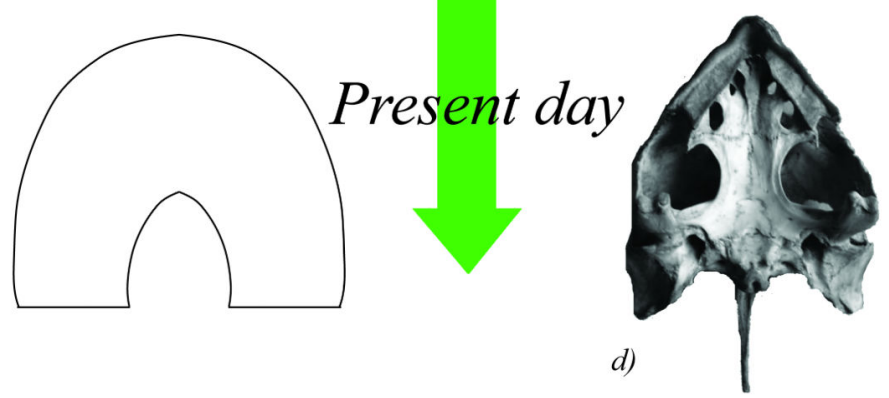

Fig. 6. The labial-to-lingual sequential loss of tooth rows in the turtle lineage Evidence in the paleontological record suggests that the turtle lineage became edentulous in a stepwise fashion: first losing the outer-most row of maxillary, premaxillary and dentary teeth, last recorded in (a) Odontochelys semitestacea, $220 \mathrm{Mya}$ (Li et al., 2008; figure adapted from same reference); then losing rows from the vomer and palatine bones, as shown in (b) Proganochelys quenstedti, 210 Mya (Gaffney and Meeker, '83; Gaffney and Jenkins, '90; figure adapted from Gaffney and Meeker, '83), and finally losing the innermost pterygoid teeth, present in (c) Kayentachelys aprix, 174-201Mya (Gaffney et al., '87; figure adapted from Gaffney and Jenkins, 2009) and Paleochersis talampayensis, 201-235Mya (not shown, Rougier et al., '95). From at least the late Jurassic, all turtle 
fossils described to date have been edentulous (Meredith et al., 2013), such as the (d) Chelydra serpentina specimen pictured here (Creative Commons). 